\section{NF-кB mediates inhibition of mesenchymal cell differentiation through a posttranscriptional gene silencing mechanism}

\author{
Raquel Sitcheran, ${ }^{1}$ Patricia C. Cogswell, ${ }^{1}$ \\ and Albert S. Baldwin Jr. 1,2,3 \\ ${ }^{1}$ Lineberger Comprehensive Cancer Center, ${ }^{2}$ Department of \\ Biology, University of North Carolina at Chapel Hill, \\ Chapel Hill, North Carolina 27599, USA
}

Cytokines, such as tumor necrosis factor- $\alpha$ (TNF $\alpha$ ), potently inhibit the differentiation of mesenchymal cells and down-regulate the expression of Sox9 and MyoD, transcription factors required for chondrocyte and myocyte development. Previously, we demonstrated that NF$\kappa B$ controls $T N F \alpha$-mediated suppression of myogenesis through a mechanism involving MyoD mRNA downregulation. Here, we show that NF- $\mathrm{B}$ also suppresses chondrogenesis and destabilizes Sox9 mRNA levels. Multiple copies of an mRNA cis-regulatory motif (5'ACUACAG-3') are necessary and sufficient for NF-кBmediated Sox9 and MyoD down-regulation. Thus, in response to cytokine signaling, NF- $\mathrm{B}$ modulates the differentiation of mesenchymal-derived cell lineages via RNA sequence-dependent, posttranscriptional downregulation of key developmental regulators.

Received May 19, 2003; revised version accepted July 24, 2003.

In multicellular organisms, control of proliferation, differentiation, and apoptosis is essential for survival. Defects in cell differentiation can lead to aberrations in other cellular processes, resulting in diseases such as cancer (Scott 1997). Mesenchymal progenitor cells give rise to the skeletal cells, including myocytes, chondrocytes, osteoblasts, and adipocytes (Pittenger et al. 1999; Caplan and Bruder 2001). Notably, cytokines such as tumor necrosis factor- $\alpha$ (TNF $\alpha$ ) can inhibit the differentiation of mesenchymal stem cells (Filipak et al. 1988; Gilbert et al. 2000) and suppress the expression of genes important for their differentiation (Guttridge et al. 2000; Murakami et al. 2000; Gilbert et al. 2002; Ruan et al. 2002). However, the molecular mechanism underlying this suppression is not known.

Nuclear factor $\kappa$ B (NF- $\mathrm{B}$ ) complexes are dimeric, sequence-specific transcription factors that regulate the expression of a large number of genes in response to a variety of cellular conditions, including infection and in-

[Keywords: NF-кB; differentiation; mesenchymal; muscle; chondrocyte; posttranscriptional control]

${ }^{3}$ Corresponding author.

E-MAIL jhall@med.unc.edu; FAX (919) 966-8212.

Article and publication are at http://www.genesdev.org/cgi/doi/10.1101/ gad.1114503. flammation (Silverman and Maniatis 2001; Ghosh and Karin 2002; Li and Verma 2002). There are five distinct NF-кB proteins, p65/RelA, c-Rel, RelB, NF-кB2/p52 and NF- $\kappa \mathrm{B} 1 / \mathrm{p} 50$, each containing a Rel homology domain that mediates DNA binding and dimerization. In the absence of stimuli, NF- $\kappa$ B is sequestered predominantly in the cytoplasm by inhibitory IкB proteins. Stimulation by effectors such as $\mathrm{TNF} \alpha$, interleukin-1 (IL-1), viral proteins, and double-stranded RNA, triggers I $\mathrm{B}$ phosphorylation and degradation, NF-кB nuclear translocation, and transcriptional regulation of target genes (Silverman and Maniatis 2001; Ghosh and Karin 2002; Li and Verma 2002). Generally, NF- $\kappa B$ is described as a transcriptional activator, and there is ample data demonstrating that NF- $\kappa$ B positively regulates transcription. However, there is also some evidence that NF- $\kappa \mathrm{B}$ can repress transcription. For example, the p50 NF- $\mathrm{B}$ subunit, which binds DNA but lacks transcriptional activation domains, may inhibit the transcription of certain genes through interaction with transcriptional corepressors such as HDAC-1 (Zhong et al. 2002).

Recently, we demonstrated that NF-кB can inhibit the differentiation of mesenchymally derived skeletal muscle cells (Guttridge et al. 2000). TNF $\alpha$-mediated activation of NF- $\mathrm{BB}$ in $\mathrm{C} 2 \mathrm{C} 12$ myoblasts led to a dramatic decrease in endogenous MyoD mRNA levels. Expression of the p65 subunit of NF- $\mathrm{BB}$ induced the loss of coexpressed MyoD message, and a fragment of the MyoDcoding sequence fused to a heterologous gene conferred NF- $\kappa$ B-dependent loss of that chimeric mRNA. These data suggested that the mechanism underlying MyoD mRNA down-regulation and inhibition of muscle-cell differentiation involves a unique posttranscriptional silencing mechanism. Cartilage, another mesenchymalderived cell lineage, is a highly specialized connective tissue that is important for skeletal development (de Crombrugghe et al. 2001; Shum and Nuckolls 2002). The transcription factor Sox 9 is required for cartilage development (Bi et al. 1999; Panda et al. 2001), and loss of Sox9 causes campomelic dysplasia, a dominant skeletal disease (Foster 1996; Schafer et al. 1996). Sox9 expression has been shown to be down-regulated by cytokines such as TNF $\alpha$ and IL-1 (Murakami et al. 2000), which may explain the deleterious role of inflammatory cytokines in diseases such as rheumatoid arthritis and osteoporosis (Fujita et al. 1990; Chen and Goeddel 2002). Cytokineinduced NF- $\mathrm{BB}$ inhibits Sox9 expression and activity (Murakami et al. 2000), however, it is not known whether this occurs at the transcriptional or posttranscriptional level. Additionally, functional characterization of the Sox9 promoter (Kanai and Koopman 1999) did not identify binding sites for NF- $\mathrm{B}$, suggesting that posttranscriptional regulatory pathways may regulate NF-кB-mediated inhibition of Sox9.

Here, we report that NF- $\mathrm{B}$ suppresses chondrogenesis and controls the loss of Sox9 mRNA. Furthermore, NFкB-mediated loss of both MyoD and Sox9 mRNAs requires a 5'-ACUACAG-3' motif present multiple times in the mRNAs. Our data can explain, at least partly, the ability of inflammatory cytokines, such as TNF $\alpha$, to suppress differentiation of mesenchymal-derived cells, and they demonstrate a novel mechanism by which NF- $\mathrm{B}$ can silence gene expression. 


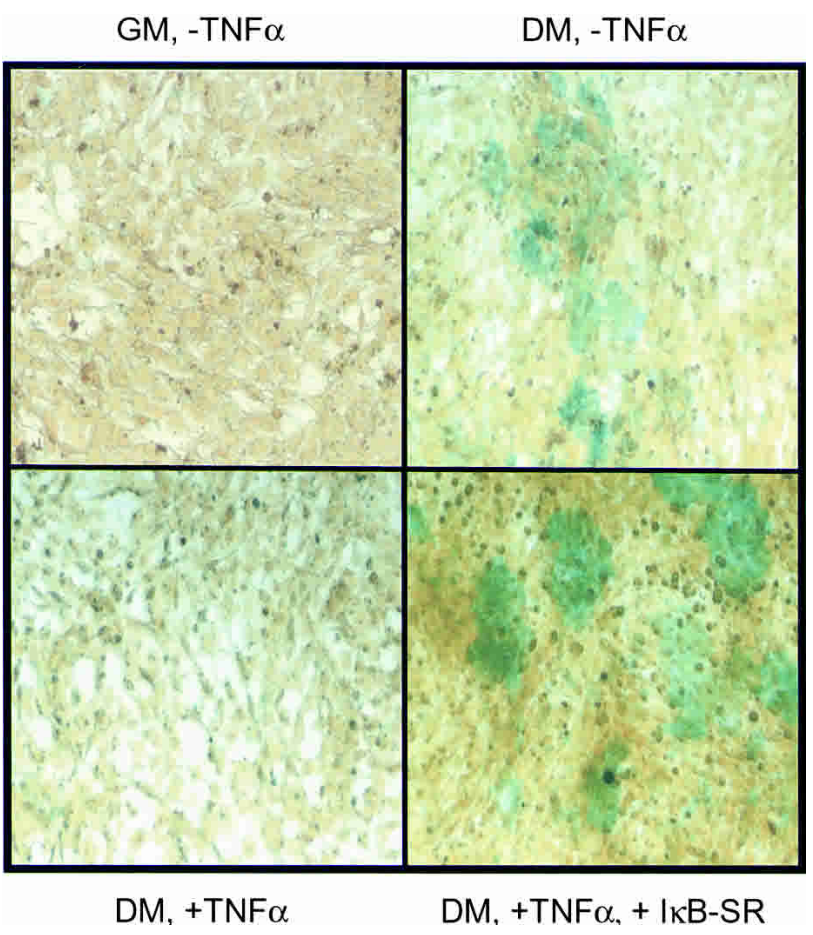

Figure 1. NF-кB inhibits mesenchymal chondrocytic differentiation in vivo. MC615 cells expressing Tet-IкB-SR were cultured in growth medium (GM) or differentiation medium (DM) and grown in the absence or presence of TNF $\alpha$ and doxycycline to induce IкB $\alpha-\mathrm{SR}$. Cells were stained with alcian blue to determine extent of matrix formation containing sulfated glycosaminoglycans, an indicator of chondrocytic differentiation. Increased alcian blue staining is seen in cells grown in DM in the absence TNF $\alpha$, as well as in the presence of TNF $\alpha$ and dox-induced IкB $\alpha-S R$. of chondrocytic differentiation (Fig. 1). In contrast, doxinduction of Iк $\mathrm{B} \alpha-\mathrm{SR}$ promoted chondrocytic differentiation in both untreated and TNF $\alpha$-treated MC615 cells grown in DM. These results demonstrate a definitive role for NF- $\kappa \mathrm{B}$ in modulating the differentiation of chondrocytic cells.

It has been reported that TNF $\alpha$ treatment of MC615 chondrocytic cells leads to the NF- $\kappa \mathrm{B}$-dependent loss of Sox9 (Murakami et al. 2000), a transcription factor that is required for cartilage differentiation. However, the mechanism underlying this process is not known. We sought to determine whether NF-кB-mediated downregulation of Sox 9 mRNA occurs through a mechanism similar to the loss of MyoD in TNF $\alpha$-induced suppression of myocyte differentiation. To address whether $\mathrm{TNF} \alpha$-mediated regulation of Sox 9 is dependent on NF$\kappa \mathrm{B}$, we first examined endogenous Sox9 expression in MC615 chondrocytic cells by Northern analysis. After reaching $80 \%-90 \%$ confluency in growth medium, MC615 cells were switched to differentiation medium for 2-3 d, and then subject to TNF $\alpha$ treatments. All cells were cultured for the same total time. Total RNA from untreated or TNF $\alpha$-treated cells were harvested and hybridized with a Sox 9 cDNA probe (Fig. 2A). Sox9 mRNA expression was potently inhibited by $\mathrm{TNF} \alpha$ treatment starting at $1 \mathrm{~h}$, with complete inhibition seen at $8 \mathrm{~h}$. Interestingly, destabilization of Sox appears to be biphasic, with an initial decrease in message at $1 \mathrm{~h}$ and a second decrease at $8 \mathrm{~h}$. The kinetics of RNA loss is similar to that observed in previously published work describing inhibition of Sox 9 mRNA by TNF $\alpha$ and IL-1 (Murakami et al. 2000). To determine whether TNF $\alpha$ induced loss of Sox9 transcript was mediated by NF- $\mathrm{B}$, we examined Sox9 expression by Northern analysis in MC615-TRexI chondrocytes stably expressing IкB $\alpha$-SR.

\section{Results and Discussion}

\section{$N F-\kappa B$ inhibits chondrocytic differentiation and mediates posttranscriptional down-regulation of Sox 9 mRNA}

Cytokines, such as TNF $\alpha$ and IL-1 can potently inhibit the differentiation of chondrocytes, the precursors of cartilage (Murakami et al. 2000). To determine whether TNF $\alpha$-mediated inhibition of differentiation of chondrocytes was mediated by or required NF- $\kappa \mathrm{B}$, we performed differentiation experiments in the chondrocytic cell line MC615-TRexI, which stably expresses a Tet-pro-

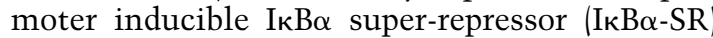
construct. We first determined that doxycycline (dox) induction of IкB $\alpha$-SR in MC615-TrexI cells blocked TNF $\alpha$-mediated NF-кB DNA-binding activity in electromobility shift assays (data not shown). Confluent cells were driven toward chondrocytic maturation by culturing in differentiation medium (DM), and we examined the formation of a cartilage-like matrix containing sulfated glycosaminoglycans by histochemical staining with Alcian blue. Cells grown in DM showed increased Alcian blue staining compared with cells grown in rich growth medium (GM). As expected, TNF $\alpha$-treated cells grown in DM showed decreased staining, indicating inhibition
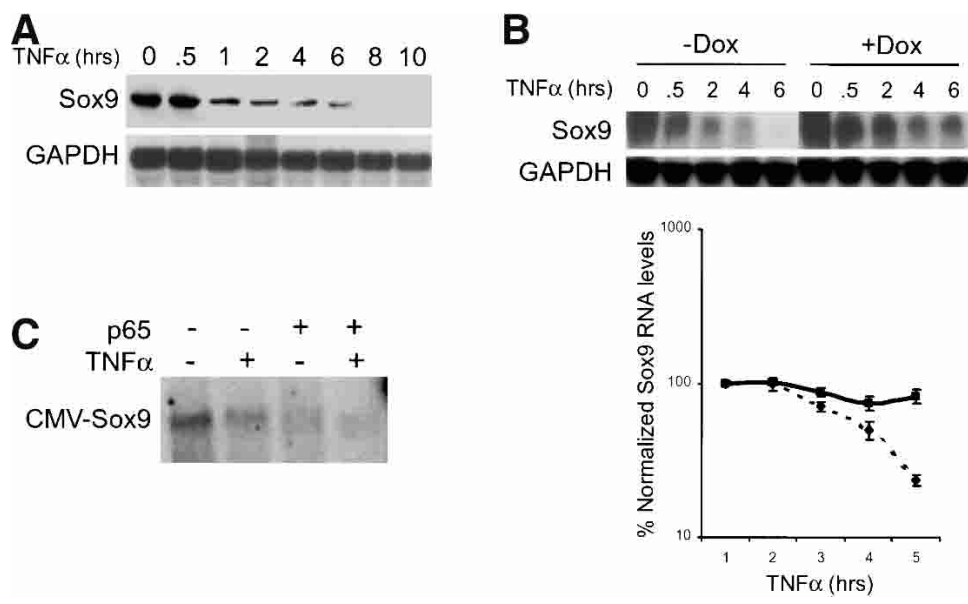

Figure 2. NF-кB regulates Sox 9 expression in chondrocytic cells. (A) TNF regulates Sox9 expression in chondrocytic cells. Total RNA from TNF $\alpha$-treated MC615 chondrocytic cells was harvested at the indicated time points and hybridized with a Sox9 cDNA probe. Loss of Sox9 mRNA is seen with TNFa treatment. $(B)$ TNF-induced loss of Sox 9 mRNA requires NF- $\mathrm{kB}$ activity. Sox 9 mRNA levels in MC615-TRexI chondrocytes stably expressing Tet-inducible I $\mathrm{B} \alpha$-SR were examined by Northern analysis. A representative blot shows stabilization of Sox 9 message in dox-treated cells. Graph shows quantitation of Sox9 transcripts relative to the zero time point (=value 100). (C) NF-кB p65 subunit mediates regulation of Sox 9 expression and does not require the Sox 9 promoter. 10T $1 / 2$ fibroblasts were transfected with a Sox 9 expression vector and either pcDNA3.1 vector or CMV-p65, $\pm \mathrm{TNF} \alpha$ treatment. Northern analysis was performed to detect Sox9 expression. 
Sitcheran et al.

We observed that Sox9 expression is inhibited with $\mathrm{TNF} \alpha$ treatment and dox-induction of $\mathrm{I} \kappa \mathrm{B} \alpha-\mathrm{SR}$ resulted in loss of sensitivity to TNF $\alpha$. These results, which are quantitated in the corresponding graph, demonstrate that NF-кB mediates down-regulation of Sox9 (Fig. 2B). The incomplete stabilization of Sox 9 mRNA may be due to incomplete inhibition of NF- $\mathrm{B}$ activity by $\mathrm{I} \kappa \mathrm{B} \alpha-\mathrm{SR}$ or to an NF-kB-independent down-regulation of Sox9 mRNA.

We next asked whether NF-kB-mediated regulation of Sox9 occurred transcriptionally through a promoterdependent mechanism and examined whether expression of a Sox9 construct under the control of the CMV promoter was affected by the p65 subunit of NF-кB. Northern analysis revealed that CMV-Sox9 expression was inhibited by either p 65 or $\mathrm{TNF} \alpha$ compared with vector control (Fig. 2C). The presence of both $\mathrm{TNF} \alpha$ and $\mathrm{p} 65$ resulted in even greater loss of Sox9 mRNA. These results demonstrate that NF-кB p65dependent down-regulation of Sox9 is not dependent on its promoter, but occurs posttranscriptionally (see below).

\section{$N F-\kappa B$ mediates posttranscriptional down-regulation of $M y o D$}

Similar to the cytokine-mediated down-regulation of Sox9, TNF $\alpha$ can down-regulate MyoD expression in an NF-kB-dependent manner (Guttridge et al. 2000). MyoD down-regulation appears to occur through a posttranscriptional mechanism on the basis of the observation that the MyoD promoter itself was not required for regulation by NF-кB. To determine whether NF-кB can regulate the transcription of the endogenous MyoD gene, nuclear run-on assays were performed. Results from these experiments demonstrated that transcription of MyoD was largely unaffected after 4 $h$ of TNF $\alpha$ treatment, despite the virtually complete loss of endogenous MyoD mRNA assayed by Northern analysis (Fig. 3A). IкB $\alpha$ exhibited increased $\mathrm{TNF} \alpha$-dependent transcription, as expected for an NF-кB-regulated gene, and GAPDH remained unchanged. Together, these results clearly establish that TNF $\alpha$-induced downregulation of MyoD mRNA occurs posttranscriptionally.

We next sought to identify the cis-regulatory elements required for NF-кB-dependent downregulation of MyoD. A fragment encompassing sequence elements from 539 to 914 of $\mathrm{MyoD}$ fused to the GADPH gene conferred NF-кB-dependent down-regulation of the chimeric RNA (Guttridge et al. 2000). To further map a minimal cis-regulatory region in the MyoD mRNA required for regulation by NF-кB, we created two smaller deletions within the 539-914 region and tested their ability to confer down-regulation on the heterologous GAPDH mRNA. Northern analysis of transiently transfected $10 \mathrm{~T}^{1} / 2$ cells showed that MyoD $\Delta 748-914-G A P D H$ is resistant to NF- $\mathrm{kB}$ regulation (Fig. 3B). In contrast, the MyoD 720-853-GAPDH construct retained sensitivity to NF- $\mathrm{\kappa B}$, thus defining a 130-nucleotide region within the MyoD mRNA as a crucial cisregulatory element.

\section{Conserved cis-regulatory elements are required for NF-кB-dependent, posttranscriptional down-regulation of Sox 9 and MyoD mRNAs}

Using a Pustell DNA matrix analysis to identify regions of similarity within MyoD 720-853 (MacVector Software), we initially discovered two 9-nucleotide motifs located near the boundaries of that fragment of the sequence 5'-ACTACAGTG-3' (written here and below as DNA sequence; Fig. 4). Another similar sequence, 5'-AtTACAGcG-3' (repeat 1.1), was found between these 9-nucleotide repeat elements. The deletion construct that eliminated the most $5^{\prime}$ of these motifs (MyoD $4748-914)$ was resistant to p65-dependent downregulation (Fig. 3B), suggesting that the first ACTA CAGTG motif plays a significant role in this process. To investigate the potential function of the 9-nucleotide motifs, we introduced point mutations within each motif in the context of the full-length MyoD sequence and tested for NF-кB-dependent degradation in transiently transfected 10T $1 / 2$ cells (Fig. 5A). Northern blot analysis revealed that point mutations generated in either motif (ACTACAGTG $\rightarrow$ ATTATTCGG) abrogated p65-dependent destabilization of MyoD mRNA, suggesting that both intact motifs are required for full NF-кB-mediated regulation of MyoD expression.

Interestingly, a core 7-nucleotide sequence (ACTA CAG), as well as other homologous nucleotides, are highly conserved in mouse and human MyoD sequences (Fig. 4A). Scanning of Sox9 for distinctive motifs revealed a 7-nucleotide repeat (ACTACAG) that is present three times within a 250-nucleotide region in the middle of the mRNA-coding sequence (Fig. 4A). This motif in Sox9 is identical to the first 7 nucleotides of the ACTAC AGTG repeat found in MyoD, and is also conserved between mouse and human Sox9 sequences, suggesting that down-regulation of Sox9 and MyoD involves similar
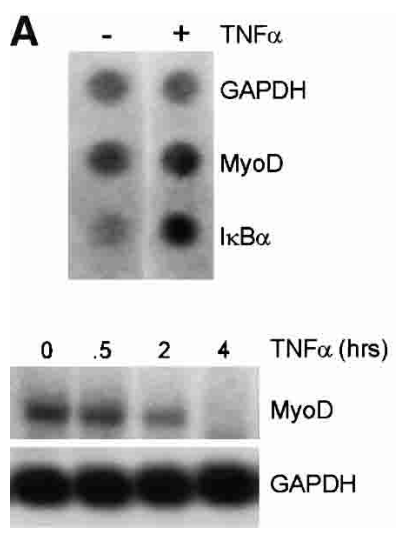

Figure 3. NF- $\mathrm{B}$ down-regulates MyoD expression via a posttranscriptional mechanism. (A) Nuclear run-on and Northern blot assays were performed to analyze MyoD expression in untreated and TNF $\alpha$-treated C2C12 cells. Transcription of GAPDH and $\mathrm{I} \kappa \mathrm{B} \alpha$ were measured as negative and positive controls for NF- $\kappa$ B activation, respectively. TNF $\alpha(4 \mathrm{~h})$ treatment does not result in significantly altered MyoD transcription, although MyoD mRNA levels are decreased by Northern assay. GAPDH expression was unaffected and ІкB $\alpha$ mRNA levels were increased by TNF $\alpha$ treatment. $(B)$ Expression analysis of different GAPDH-MyoD fusion constructs were performed by Northern analysis of RNA from transiently transfected 10T $1 / 2$ cells. The MyoD (539-914)-GAPDH fusion is down-regulated by p65 (cf. lanes 1 and 2). A construct containing a deletion of a region containing the 9-nucleotide motifs, MyoD (D748-D914), is insensitive to regulation by NF-кB. A 133-nucleotide fragment containing both motifs, MyoD (720-853)-GAPDH is down-regulated in a p65-dependent manner. 
A

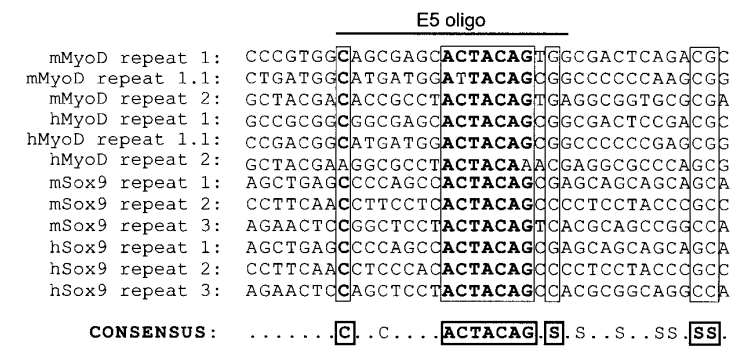

B

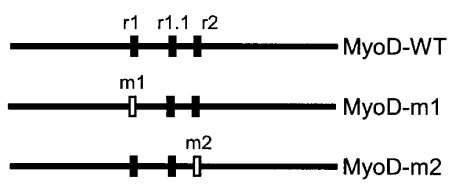

ACTACAGTG - wild type MyoD repeat ATTATTCGG- mutant MyoD repeat

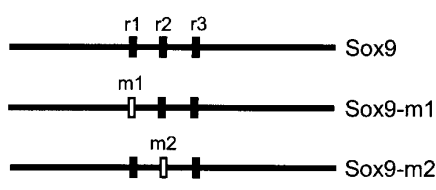

ACTACAG - wild type Sox9 repeat ATTATTC- mutant Sox9 repeat
Figure 4. The coding sequences of MyoD and Sox 9 contain multiple ACTCAG motifs. (A) Sequence alignment of repeat motifs in MyoD and Sox9 mouse and human sequences. Conserved nucleotides indicated with bold type. $S$ represents C or G. The E5 oligo used in the experiment shown in Figure $5 B$ is indicated. $(B)$ Position and spacing of wild-type and mutant repeat motifs within MyoD and Sox9. Sequence of wild-type and mutant repeats is shown with mutated nucleotides in bold.

mechanisms. Given the similarity of the motifs present in both MyoD and Sox9, we investigated whether the 7-nucleotide motifs present in Sox9 were required for regulation by NF- $\mathrm{KB}$. We introduced mutations into the first repeat sequence $($ ACTACAG $\rightarrow$ ATTATTC, see Fig. 4B) and analyzed Sox 9 expression in the absence or presence of p65. Whereas the wild-type Sox9 sequence is down-regulated in the presence of p65, mutation of either the first and second ACTACAG motif (Sox9-m1) stabilized the Sox9 mRNA (Fig. 5B).

To determine whether the ACTACAG motifs could specify down-regulation by NF- $\mathrm{kB}$, we introduced an oligonucleotide containing a single motif into two positions within GAPDH and assayed their effect on the stability of the chimeric GAPDH mRNA (Figs. 4A, 5C). The oligos were spaced 125 nucleotides apart within the central coding region of GAPDH, similar to the spacing of the motifs within MyoD. After transient transfection of $10 \mathrm{~T}^{1 / 2}$ cells, we examined the expression of wild-type and chimeric GAPDH transcript (E5) by Northern analysis. The expression of GAPDH-E5 was similar to wildtype GAPDH (Fig. 5C, lanes 3,5). We observed almost complete destabilization of the GAPDH-E5 transcript in the presence of $\mathrm{p} 65$, whereas both the wild-type construct, as well as endogenous GAPDH, remained unaffected by p65 expression (Fig. 5C, lanes 4,6). The ability of the E5 oligo to confer p65-mediated down-regulation of GAPDH, a transcript that is not typically regulated by NF- $\mathrm{B}$, demonstrates that this short sequence containing the ACTACAG motifs is sufficient to generate an NF-кB response. These results suggest that the ACTACAG motifs represent, presumably indirect, NF-кBresponsive elements in the MyoD and Sox9 mRNAs (also see below). In sum, our results indicate that the conserved ACTACAG motifs are both necessary and sufficient for NF-кB-mediated Sox9 and MyoD down-regulation, demonstrating a novel mechanism by which NF- $\kappa \mathrm{B}$ regulates gene expression and modulates cell differentiation.

\section{Conclusions}

Our data demonstrate that NF-кB can modulate the differentiation status of mesenchymal-derived cell lineages in response to cytokine signaling, and that NF-kB-dependent inhibition of chondrocytic and myocytic differentiation occurs through the posttranscriptional down-regulation of the key developmental regulators, Sox 9 and MyoD. Using mutagenesis experiments, we have established that this down-regulation requires a novel ACTACAG motif found multiple times in the coding region of both mRNAs, and demonstrated that a short oligo containing this motif is sufficient to confer NF- $\mathrm{KB}$-dependent destabilization of a heterologous mRNA. Interestingly, the ACTACAG heptamer, as well as some additional nucleotides close to each motif, is conserved in both mouse and human MyoD and Sox9 sequences (Fig. 4). The significance of the additional conserved nucleotides remains to be determined. It is also not clear whether the localization or spacing of the repeat elements within the coding regions of Sox9 and MyoD is significant. The ACTACAG motif may form a binding site for a factor that regulates the stability of Sox9 and MyoD mRNAs. Preliminary secondary structure analysis using Mfold 3.0 (M. Zuker, Washington University, and the NRCC) suggests that the ACTACAG motif may form part of a stem-loop structure. However, because NF- $\mathrm{\kappa B}$ transcriptional activity is required for down-regulation of MyoD (Guttridge et al. 2000), it is likely that NF- $\mathrm{BB}$ does not directly interact with this motif, but rather, induces the expression of a factor that regulates RNA stability. This hypothetical factor could directly promote RNA degradation, or inhibit RNA stability.

Several studies indicate that NF-кB can inhibit gene expression in other mesenchymal cell lineages. For example, it has been shown that TNF $\alpha$ stimulation of adipocytes suppressed expression of adipocytic genes, including PPAR $\gamma$, as well as induced pre-adipocytic genes, in an NF-кB-dependent manner (Xing et al. 1997; Ruan et al. 2002). It has also been reported that TNF $\alpha$-mediated down-regulation of the transcription factor Runx2/CbfaI, which is required for osteoblast differentiation (Karsenty 2001; Komori 2002), occurs at multiple levels, including RNA destabilization and transcriptional repression (Gilbert et al. 2002). Interestingly, the Runx2/Cbfa1 mRNAcoding sequence contains similar, but not perfect, AC TACAG motifs. Thus, it seems likely that both transcriptional and posttranscriptional mechanisms may be used by NF-кB to regulate the differentiation of other mesenchymal lineages and/or the expression of other genes. It will be important to determine the breadth of the NF-кB-mediated, posttranscriptional down-regulation of mRNAs through this RNA sequence-dependent mechanism in order to relate this process to inflammatory disorders and oncogenesis.

\section{Materials and methods}

Constructs

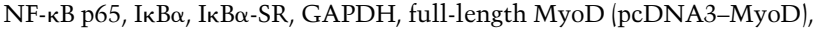
and MyoD (539-914) and MyoD 539-914-GAPDH fusion constructs 


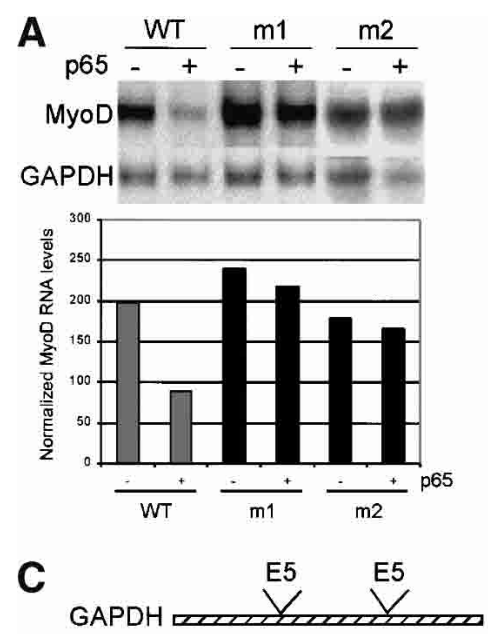

E5 oligo: cagcgagCACTACAGTGg

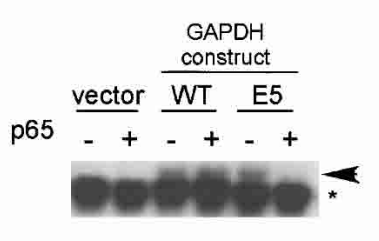

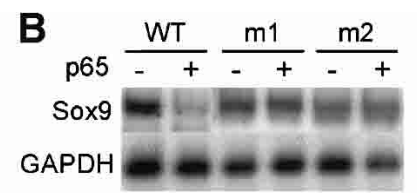


Figure 5. The ACTACAG motifs are required for NF-кB-dependent mRNA destabilization. Representative Northern blots are shown with data quantitated in corresponding graphs. (A) MyoD mutants were generated within the context of the full-length coding sequence (see Fig. 4B). 10T $1 / 2$ cells were transfected with wild-type or mutant MyoD constructs and with or without p65. MyoD constructs with mutations in either motif $(\mathrm{m} 1$ or $\mathrm{m} 2)$ are largely resistant to $\mathrm{p} 65$ mediated down-regulation compared with wild-type MyoD. (B) A 7-nucleotide motif in Sox9 is similar to the 9-nucleotide MyoD motif and required for efficient down-regulation by NF-кB. Mutations in Sox 9 were generated within the context of the full-length coding sequence. The Sox $9 \mathrm{~m} 1$ and $\mathrm{m} 2$ mutants were insensitive to down-regulation by p65 compared with wild-type Sox9. (C) A short oligonucleotide containing the ACTACAG motif is sufficient to confer p65-dependent destabilization of GAPDH-E5. The sequence and position of the E5 oligo is shown. Transfected constructs are indicated by an arrow. Endogenous GAPDH expression is indicated with an asterisk.

were described previously (Guttridge et al. 2000). MyoD $\Delta 748-914$ was created by excising a 75-nucleotide fragment in pcDNA-GAPDH-MyoD 539-914 with NarI and MluI, filling in and religating the plasmid. The deletion maintains an ORF within the mouse MyoD fragment. MyoD 720-853 fragment was PCR amplified from pcDNA3-MyoD using the following oligos: 5'-CTGCAGAACCAAAGGCTTGGCAGCGAGCAC TACAGT-3' and '5'-ATGCATCCAAAGGCTTTGCACTGTAGTAGG CGGTGT-3', digested with BstXI and subcloned into the GAPDH BstXI site. Full-length mouse Sox 9 was amplified by reverse transcriptase PCR (RT-PCR) from MC615 total RNA, with the following oligos: 5'CGAATTCCGTATGAATCTCCTGGACCC- ${ }^{\prime}$ ' and $5^{\prime}$-CGGGATCCAT CATCTCGGCCATCGTCG-3', and subcloned into pcDNA3.1 vector (Invitrogen). pcDNA3-MyoD and Sox 9 mutant constructs were made using the QuikChange Site-Directed Mutagenesis Kit (Stratagene) with the primers for MyoD (mMD-1/5', CCCCCGGGCCGTGGCAGCGAG CATTATTCGGGCGACTCAGACGCG; mMD-1/3', CGCGTCTGAGT CGCCCGAATAATGCTCGCTGCCACGGCCCGGGG; mMD-2/5', GG CTACGACACCGCCTATTATTCGAGGCGGTTCGCGAGTCC; mMD2/3', GGACTCGCGAACCGCCTCCGAATAATAGGCGGTGTCGTA GCC) and for Sox9. Mutated nucleotides are indicated in bold. Tet-

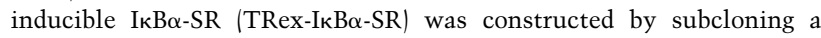
HindIII/SmaI human IкB $\alpha$-SR fragment into the HindIII/SmaI of pcDNA/ TO/Myc/HisA (Invitrogen). For GAPDH-E5, first oligos 5'-CATG GCAGCGAGCACTACAGTGGA-3' and 5'-CATGTCCACTGTAGTG CTCGCTGC-3' were annealed and subcloned into GAPDH NcoI site, then oligos 5'-CCAGCGAGCACTACAGTGGATGCA-3' and 5'-
TCCACTGTAGTGCTCGCTGGTGCA-3' were annealed and subcloned into GAPDH NsiI site.

Cell culture and histochemical analysis

$\mathrm{C} 2 \mathrm{C} 12$ and $10 \mathrm{~T}^{1} \frac{1}{2}$ cells were obtained from ATTC. Dr. B. Olsen kindly provided the chondrocytic cell line, MC615 (MalleinGerin and Olsen 1993). C2C12 and MC615 cells were maintained in growth medium (GM) containing DMEM-H, $20 \%$ fetal bovine serum, $100 \mu \mathrm{g} / \mathrm{mL}$ penicillin and $100 \mu \mathrm{g} / \mathrm{mL}$ streptomycin (Sigma). For C2C12 myogenic differentiation, cells were changed to DMEM containing $2 \%$ horse serum, $5 \mu \mathrm{g} / \mathrm{mL}$ insulin and pen/strep. For MC615 chondrocytic differentiation, cells were grown to $80 \%-90 \%$ confluency and changed to differentiation medium [DM: DMEM-H 5\% FCS containing $50 \mu \mathrm{g} / \mathrm{mL}$ ascorbic acid (Invitrogen)], and $10 \mathrm{mM} \beta$-glycerophosphate (Sigma) for 2-3 d. NF-kB activation was induced with $20 \mathrm{ng} / \mathrm{mL}$ rhTNF $\alpha$ (Promega). Transient transfections were carried out using Fugene6 (Roche) according to the manufacturer's instructions. MC615 stably expressing IкB-SR (MC615-TRexI) were generated with the TRex system (Invitrogen). Briefly, MC615 cells were cotransfected with TRex-IkB-SR and pcDNA6/TR, which expresses the Tet repressor under the control of the human CMV promoter. Stable integrants were selected with Blasticidin $(5 \mu \mathrm{g} / \mathrm{mL})$ and Zeocin $(250 \mu \mathrm{g} / \mathrm{mL})$ and individual clones were tested for tetracycline/doxycycline induction of IкB $\alpha$-SR expression by Western blot (data not shown).

Chondrogenic differentiation was determined by staining of sulfated glycosaminoglycans with Alcian Blue 8GX (pH 1, Sigma), as described (Asahina et al. 1996). Briefly, cells were washed with PBS, fixed with $4 \%$ paraformaldehyde for $10 \mathrm{~min}$, and stained with $0.5 \%$ Alcian Blue 8GX in $0.1 \mathrm{~N} \mathrm{HCl} \mathrm{overnight.}$ Nuclear run-on assays

For each condition, $4 \times 10^{6}$ cells were harvested and incubated on ice for $3 \mathrm{~min}$ in lysis buffer (10 mM Tris-HCL at pH 7.4, 10 $\mathrm{mM} \mathrm{NaCl}, 3 \mathrm{mM} \mathrm{MgCl} 2,0.5 \%$ NP-40). Nuclei were pelleted by centrifugation at 500g, resuspended in $100 \mu \mathrm{L}$ Nuclear Freezing buffer (50 mM Tris-HCl at $\mathrm{pH} 8.3,40 \%$ glycerol, $5 \mathrm{mM} \mathrm{MgCl}_{2}$, $0.1 \mathrm{mM}$ EDTA at $\mathrm{pH}$ 8) and either frozen at $-80^{\circ} \mathrm{C}$ or used immediately. For the run-on reaction, $30 \mu \mathrm{L}$ of $5 \times$ Run-on buffer (25 mM Tris- $\mathrm{HCl}$ at $\mathrm{pH} 8 ; 12.5 \mathrm{mM} \mathrm{MgCl} 2 ; 750 \mathrm{mM} \mathrm{KCl} ; 1.25$ $\mathrm{mM}$ each of ATP, GTP, and CTP; and $\left.100 \mu \mathrm{Ci}\left[\alpha^{32} \mathrm{P}\right] \mathrm{UTP}\right)$ and $0.06 \%$ Sarkosyl was added to $100 \mu \mathrm{L}$ of nuclei on ice. Reactions were allowed to proceed at $30^{\circ} \mathrm{C}$ for $30 \mathrm{~min}$, after which DNase I (Promega) was added and incubation proceeded for another 15 min. at $30^{\circ} \mathrm{C}$. RNA was isolated from nuclei with Trizol (Invitrogen). Plasmid fragments were electrophoresed and dot-blotted on nylon membrane. Membranes were hybridized with $3 \times 10^{6}$ cpm of transcribed RNA for 16-24 h, then washed three to four times with $2 \times$ SSC, and analyzed by autoradiography.

\section{Northern blot assays}

Total RNA was isolated from cells from a confluent 100-mm plate using Trizol (Invitrogen). 5-20 $\mu$ g of RNA was electrophoresed on a denaturing formaldehyde gel and transferred onto a nylon membrane (HyBond-NX, Amersham). RNAs were UV-cross-linked to the membrane and hybridized using ExpressHyb (Clontech) according to the manufacturer's instructions. Northern blot data was quantitated using Scion Image (NIH), normalized to endogenous GAPDH levels and multiplied by a factor of 100 for presentation purposes. Experiments were repeated at least three times.

\section{Acknowledgments}

We are grateful to Denis Guttridge for MyoD constructs and interesting scientific discussions and Ahmad Amin for assistance in generating the MC615-TRexI cells. We thank Hubert Amrein and Kris Steinbrecher for critical reading of the manuscript. This work was funded by NIH grants AI35098 and CA73756 to A.S.B. R.S. is funded by a Cancer Research Institute postdoctoral fellowship.

The publication costs of this article were defrayed in part by payment of page charges. This article must therefore be hereby marked "advertisement" in accordance with 18 USC section 1734 solely to indicate this fact. 


\section{References}

Asahina, I., Sampath, T.K., Hauschka, P.V. 1996. Human osteogenic protein-1 induces chondroblastic, osteoblastic, and/or adipocytic differentiation of clonal murine target cells. Exp. Cell. Res. 222: 38-47.

Bi, W., Deng, J.M., Zhang, Z., Behringer, R.R., and de Crombrugghe, B. 1999. Sox9 is required for cartilage formation. Nat. Genet. 22: 85-89.

Caplan, A.I. and Bruder, S.P. 2001. Mesenchymal stem cells: Building blocks for molecular medicine in the 21st century. Trends Mol. Med. 7: 259-264.

Chen, G. and Goeddel, D.V. 2002. TNF-R1 signaling: A beautiful pathway. Science 296: 1634-1635.

de Crombrugghe, B., Lefebvre, V., and Nakashima, K. 2001. Regulatory mechanisms in the pathways of cartilage and bone formation. Curr. Opin. Cell. Biol. 13: 721-727.

Filipak, M., Sparks, R.L., Tzen, C.Y., and Scott, R.E. 1988. Tumor necrosis factor inhibits the terminal event in mesenchymal stem cell differentiation. J. Cell. Physiol. 137: 367-373.

Foster, J.W. 1996. Mutations in SOX9 cause both autosomal sex reversal and campomelic dysplasia. Acta Pediatr. Jpn. 38: 405-411.

Fujita, T., Matsui, T., Nakao, Y., Shiozawa, S., and Imai, Y. 1990. Cytokines and osteoporosis. Ann. NY Acad. Sci. 587: 371-375.

Ghosh, S. and Karin, M. 2002. Missing pieces in the NF-кB puzzle. Cell 109: $\mathrm{S} 81-\mathrm{S} 96$.

Gilbert, L., He, X., Farmer, P., Boden, S., Kozlowski, M., Rubin, J., and Nanes, M.S. 2000. Inhibition of osteoblast differentiation by tumor necrosis factor- $\alpha$. Endocrinology 141: 3956-3964.

Gilbert, L., He, X., Farmer, P., Rubin, J., Drissi, H., van Wijnen, A.J., Lian, J.B., Stein, G.S., and Nanes, M.S. 2002. Expression of the osteoblast differentiation factor RUNX2 (Cbfa1/AML3/Pebp2 $\alpha$ A) is inhibited by tumor necrosis factor- $\alpha$. J. Biol. Chem. 277: 2695-2701.

Guttridge, D.C., Mayo, M.W., Madrid, L.V., Wang, C.Y., and Baldwin Jr., A.S. 2000. NF-кB-induced loss of MyoD messenger RNA: Possible role in muscle decay and cachexia. Science 289: 2363-2366.

Kanai, Y. and Koopman, P. 1999. Structural and functional characterization of the mouse Sox 9 promoter: Implications for campomelic dysplasia. Hum. Mol. Genet. 8: 691-696.

Karsenty, G. 2001. Minireview: Transcriptional control of osteoblast differentiation. Endocrinology 142: 2731-2733.

Komori, T. 2002. Runx2, a multifunctional transcription factor in skeletal development. J. Cell. Biochem. 87: 1-8.

Li, Q. and Verma, I.M. 2002. NF-kB regulation in the immune system. Nat. Rev. Immunol. 2: 725-734.

Mallein-Gerin, F. and Olsen, B.R. 1993. Expression of simian virus 40 large $\mathrm{T}$ (tumor) oncogene in mouse chondrocytes induces cell proliferation without loss of the differentiated phenotype. Proc. Natl. Acad. Sci. 90: 3289-3293.

Murakami, S., Lefebvre, V., and de Crombrugghe, B. 2000. Potent inhibition of the master chondrogenic factor Sox9 gene by interleukin-1 and tumor necrosis factor- $\alpha$. J. Biol. Chem. 275: 3687-3692.

Panda, D.K., Miao, D., Lefebvre, V., Hendy, G.N., and Goltzman, D. 2001. The transcription factor SOX9 regulates cell cycle and differentiation genes in chondrocytic CFK2 cells. J. Biol. Chem. 276: 41229-41236.

Pittenger, M.F., Mackay, A.M., Beck, S.C., Jaiswal, R.K., Douglas, R., Mosca, J.D., Moorman, M.A., Simonetti, D.W., Craig, S., and Marshak, D.R. 1999. Multilineage potential of adult human mesenchymal stem cells. Science 284: 143-147.

Ruan, H., Hacohen, N., Golub, T.R., Van Parijs, L., and Lodish, H.F. 2002. Tumor necrosis factor- $\alpha$ suppresses adipocyte-specific genes and activates expression of preadipocyte genes in 3T3-L1 adipocytes: Nuclear factor-кB activation by TNF- $\alpha$ is obligatory. Diabetes 51 : 1319-1336.

Schafer, A.J., Foster, J.W., Kwok, C., Weller, P.A., Guioli, S., and Goodfellow, P.N. 1996. Campomelic dysplasia with XY sex reversal: Diverse phenotypes resulting from mutations in a single gene. Ann. NY Acad. Sci. 785: 137-149.

Scott, R.E. 1997. Differentiation, differentiation/gene therapy and cancer. Pharmacol. Ther. 73: 51-65.

Shum, L. and Nuckolls, G. 2002. The life cycle of chondrocytes in the developing skeleton. Arthritis Res. 4: 94-106.

Silverman, N. and Maniatis, T. 2001. NF-кB signaling pathways in mammalian and insect innate immunity. Genes \& Dev. 15: 2321-2342.
Xing, H., Northrop, J.P., Grove, J.R., Kilpatrick, K.E., Su, J.L., and Ringold, G.M. 1997. TNF $\alpha$-mediated inhibition and reversal of adipocyte differentiation is accompanied by suppressed expression of PPAR $\gamma$ without effects on Pref-1 expression. Endocrinology 138: 2776-2783.

Zhong, H., May, M.J., Jimi, E., and Ghosh, S. 2002. The phosphorylation status of nuclear NF-к B determines its association with $\mathrm{CBP} / \mathrm{p} 300$ or HDAC-1. Mol. Cell 9: 625-636. 


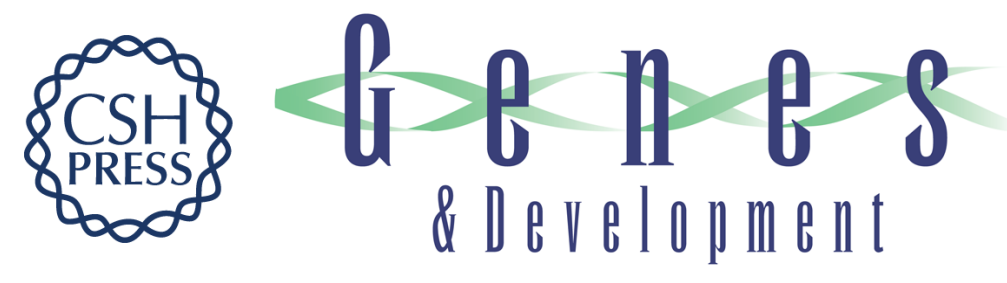

\section{NF- $\kappa B$ mediates inhibition of mesenchymal cell differentiation through a posttranscriptional gene silencing mechanism}

Raquel Sitcheran, Patricia C. Cogswell and Albert S. Baldwin, Jr.

Genes Dev. 2003, 17:

Access the most recent version at doi:10.1101/gad.1114503

Related Content

References

\section{License}

\section{Posttranscriptional Regulation by NF-oB}

Sci. STKE October , 2003 2003: tw397-TW397

This article cites 26 articles, 9 of which can be accessed free at:

http://genesdev.cshlp.org/content/17/19/2368.full.html\#ref-list-1

Articles cited in:

http://genesdev.cshlp.org/content/17/19/2368.full.html\#related-urls

\section{Email Alerting
Service \\ Email Alerting
Service}

Receive free email alerts when new articles cite this article - sign up in the box at the top right corner of the article or click here.



